\title{
Increase of fecundity by probiotic administration in zebrafish (Danio rerio)
}

\author{
Giorgia Gioacchini ${ }^{1}$, Francesca Maradonna ${ }^{1}$, Francesco Lombardo ${ }^{1}$, Davide Bizzaro², \\ Ike Olivotto ${ }^{1}$ and Oliana Carnevali ${ }^{1}$ \\ Departments of ${ }^{1}$ Marine Sciences and ${ }^{2}$ Biochemistry, Biology and Genetics, Polytechnic University of Marche, \\ via Brecce Bianche, 60131 Ancona, Italy \\ Correspondence should be addressed to O Carnevali; Email: o.carnevali@univpm.it
}

\begin{abstract}
It is well known established that reproduction is sensitive to the state of energy reserves, and that there is a balance between energy homeostasis and fertility. In this view, this study examined the effects of the probiotic Lactobacillus rhamnosus, as a feed additive, on zebrafish (Danio rerio) fecundity. Ten days of probiotic treatment modulate the gene expression of neuropeptide hormones and metabolic signals, such as kiss1, kiss2 and leptin both at the CNS level and at the peripheral level. The increase in fecundity brought about by the probiotic was demonstrated by the higher number of ovulated eggs in vivo and by the higher germinal vesicle breakdown rate obtained with the in vitro maturation assay. The increase in oocyte maturation was associated with increased transcription of genes coding for signals which induce the maturation phase, such as Ihcgr, cbr1I, and paqr8 genes, concomitant with a decreased transcription of genes coding for local factors which prevent oocyte maturation, such as tgfb1, gdf9, and bmp15. In conclusion, all these findings highlight the action of $L$. rhamnosus both on the endocrine system and at the local level by inducing oocyte maturation. The significance of the results herein obtained underlined the importance of diet in the reproductive process, supporting the hypothesis that feed additives can improve fecundity. Considering that the zebrafish has been clearly established as a vertebrate model for biomedical research, these results support the potentiality of feed additives such as probiotics, frequently used in the human diet, as a new technology to improve reproduction in all vertebrates, including humans.
\end{abstract}

Reproduction (2010) 140 953-959

\section{Introduction}

Over the past 20 years, the zebrafish (Danio rerio) has attracted considerable attention as an excellent vertebrate model system for studying genetics and development (Fishman 2001), and more recently, for understanding human disease and for the screening of therapeutic drugs (Penberthy et al. 2002, Sumanas \& Lin 2004, Keller et al. 2006, Shiels et al. 2009).

Zebrafish have asynchronous ovaries, containing follicles at all stages of development (Selman et al. 1993) as well as mature eggs. The growth and maturation of the oocyte occur over a period of about 10 days (Wang \& Ge 2003a, 2003b), and in laboratory conditions, eggs are spawned throughout the year.

In zebrafish, as in all vertebrates, reproduction is regulated by the hypothalamus-pituitary-gonadal axis. The hypothalamus, integrating internal and external stimuli, releases Gnrh (Zohar et al. 2010). In recent years, it has been established that Gnrh transcription and secretion are gated by the state of energy reserves in the organism (Hill et al. 2008). The impact of energy status on the reproductive axis is conveyed through a number of neuropeptide hormones and metabolic signals, such as kiss1, kiss2, and leptin, whose nature and mechanisms of action have begun to be deciphered only in recent years in mammals and, to a lesser extent, in fish (Fernandez-Fernandez et al. 2006, Castellano et al. 2009, Kitahashi et al. 2009). Under the influence of Gnrh, the pituitary secretes Fsh and Lh, which act upon the gonads controlling follicle growth and maturation (Nagahama etal. 1995, Patino et al. 2001). In particular at ovarian level, Lh, through its receptor (Ihcgr), stimulates the production of $17 \alpha$-hydroxyprogesterone that is converted (by the action of $c b r 1 /$ ) into $17 \alpha, 20 \beta$-dihydroxy4-pregnen-3-one, the maturation-inducing hormone $(\mathrm{MIH})$ in zebrafish (Patino et al. 2001). The binding of $\mathrm{MIH}$ to its receptors (paqr $7 b$ and paqr8) activates the maturation processes (Hanna \& Zhu 2009).

Oocyte maturation is regulated not only by the endocrine system but also by the auto/paracrine factors such as the transforming growth factor $\beta$ (Tgfb) superfamily. Tgfb is a large group of oocyte maturation regulatory molecules that include positive factors such as inhibins/activins and negative factors such as tgfb 1 , bone morphogenetic protein 15 (bmp15), and growth 
and differentiation factor 9 (gdf9; Liu \& Ge 2007, Clelland \& Peng 2009, Tan et al. 2009).

This study investigated for the first time the effects of probiotic Lactobacillus rhamnosus administration on fecundity and on the endocrine and paracrine control of follicle development in female zebrafish.

According to the $\mathrm{WHO}$ definition, probiotic bacteria are 'live microorganisms which when administered in adequate amounts confer a health benefit on the hosts'. L. rhamnosus was selected in this study since it is a common constituent of the indigenous microbiota in the intestinal and urogenital tracts of mammals and other vertebrates and is able to balance the intestinal microbiota, inducing host immunomodulation and decreasing the symptoms of a wide range of gastrointestinal disorders (Manley et al. 2007, Pant et al. 2007, Szajewska et al. 2007, Verdenelli et al. 2009).

At a physiological level, a 10-day administration of L. rhamnosus had an effect on the number of ovulated eggs and on the hatching rate. At a molecular level, this administration affected the expression of molecules that control the balance between energy homeostasis and fecundity as well as the expression of molecules that control follicle maturation at brain, gut, and ovarian levels. Concomitantly with these molecular changes, the in vitro maturation assay revealed a higher rate of germinal vesicle breakdown (GVBD) in oocytes from females administered with this probiotic.

\section{Results}

\section{Effects of $\mathrm{L}$. rhamnosus on metabolic control of reproduction}

Figs 1 and 2 show the endocrine control of reproduction as a result of $L$. rhamnosus administration. In zebrafish, both at the gut and at the brain levels, probiotic administration induced a significant increase in the gene expression of leptin, a key hormone in energy homeostasis and neuroendocrine functions (Fig. 1A

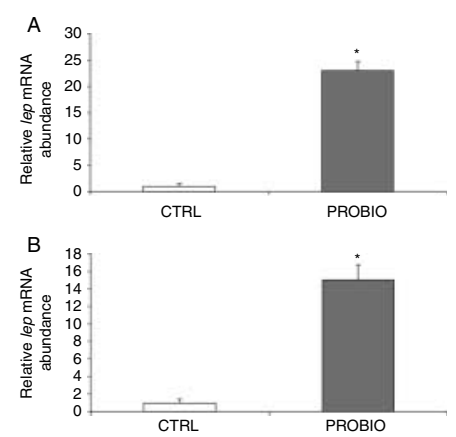

Figure 1 (A) lep mRNA levels in the gut and (B) in the brain, normalized against $\beta$-actin and gapdh genes, in females fed on $L$. rhamnosus (PROBIO) and in control females (CTRL). Data are given as mean \pm s.D. $(n=3)$. Asterisks denote significant differences from the control group $(P<0.05)$ analyzed using Student's $t$-test.
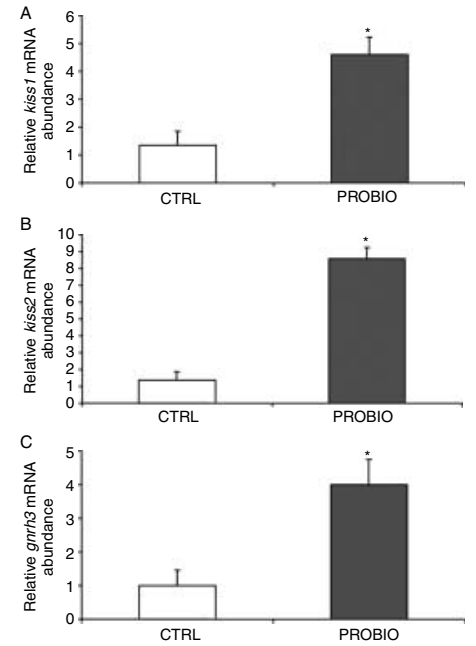

Figure 2 (A) kiss1, (B) kiss2, and (C) gnrh3 mRNA levels in the brain, normalized against $\beta$-actin and gapdh genes, in females fed on L. rhamnosus (PROBIO) and in control females (CTRL). Data are given as mean \pm s.D. $(n=3)$. Asterisks denote significant differences from the control group $(P<0.05)$ analyzed using Student's $t$-test.

and B). This increase was correlated with a significant rise in the brain gene expression of kiss 1 and kiss2: these newly discovered neuropeptides can control Gnrh expression, representing the link between metabolic and reproductive systems (Fig. 2A and B). The increase in neuropeptides mRNA was concomitant with an increase in gnrh3 gene expression, as reported in Fig. 2C.

\section{Effects of L. rhamnosus on oocyte maturation and fecundity}

In zebrafish adults, L. rhamnosus administration significantly increased fecundity (Fig. 3). The number of ovulated eggs per day rose significantly as a result of the probiotic treatment, starting from the second day of administration. In particular, the number of ovulated eggs by the treated females reached the maximum on day 2, with eggs production remaining high during the following days (Fig. 3). The induction of follicle maturation was concomitant with a significant decrease in the expression of genes coding for signals involved in the prevention of premature oocyte maturation such as tgfb1, bmp15, and gdf9 (Fig. 4A-C). The decrease in tgfb 1 and bmp15 found in the ovaries of females fed on the probiotic was concomitant with the positive control on $/$ chgr, cbr1l, and paqr8 gene transcription (Fig. 5A-C), all of which are important signals involved in the induction of oocyte maturation. The involvement of probiotic on follicle development was also supported by histological studies. The ovarian sections evidenced an increase of vitellogenic follicles in fish treated with probiotic (Fig. 6). The improvement in follicle maturation 


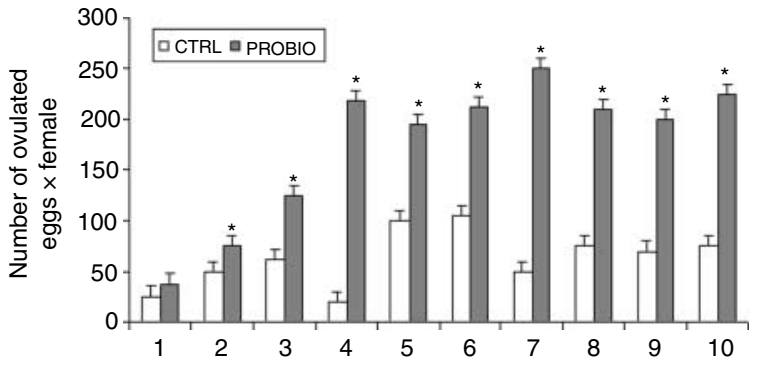

Figure 3 The count of number (10 days of treatment) of eggs spawned per day by females fed on $L$. rhamnosus (PROBIO) and by control females (CTRL) was performed every day at $0900 \mathrm{~h}$ within $1 \mathrm{~h}$ after lights. Data are given as mean \pm s.D. $(n=5)$. Asterisks denote significant differences from the control group $(P<0.05)$ analyzed using Student's $t$-test.

was also confirmed by the in vitro GVBD. Stage IIIb follicles isolated from the ovaries of treated females incubated with $\mathrm{MIH}$ showed the greatest rate of GVBD, while probiotic administration alone had no stimulatory effect (Fig. 7).

The molecular data (Figs 4 and 5) and the significant increase in the number of ovulated eggs per day (Fig. 3) observed suggest that $L$. rhamnosus administration as a feed additive promotes oocyte maturation. Moreover, this increase in follicle maturation due to probiotic administration did not negatively affect the egg quality since the embryos produced by females fed with the probiotic showed the highest hatching rate (Fig. 8) and a faster embryo development, characterized by the fact that embryo hatching was brought forward by $4 \mathrm{~h}$ (Table 1).

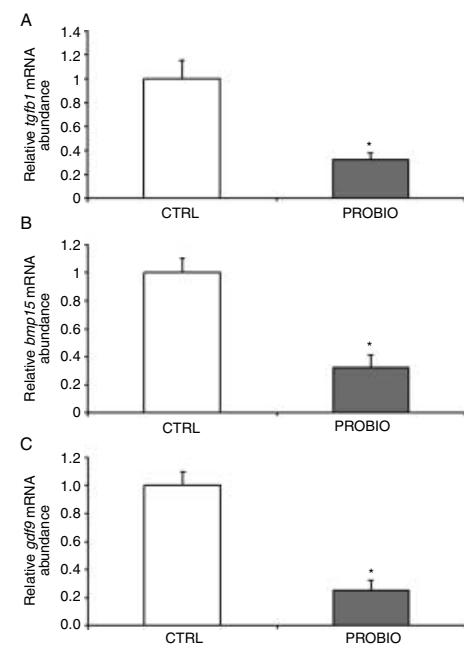

Figure 4 (A) tgfb1, (B) bmp15, and (C) gdf9 mRNA levels in the ovary, normalized against $\beta$-actin and gapdh genes in females fed on $L$. rhamnosus (PROBIO) and in control females (CTRL). Data are given as mean \pm s.D. $(n=3)$. Asterisks denote significant differences from the control group $(P<0.05)$ analyzed using Student's $t$-test.

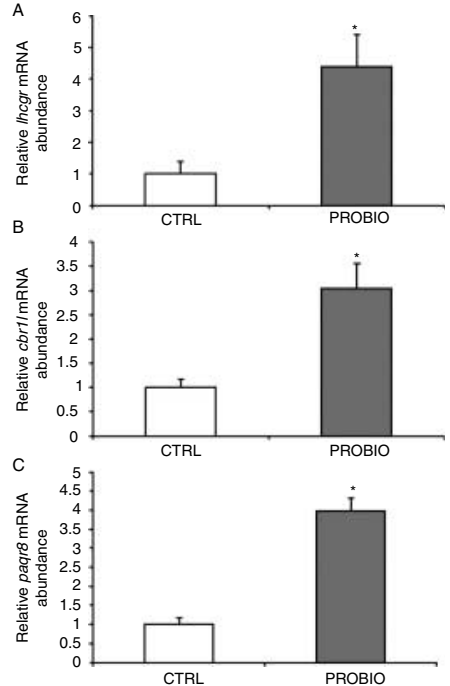

Figure 5 (A) Ihcgr, (B) cbr1l, (C) paqr8 mRNA levels in the ovary, normalized against $\beta$-actin and gapdh genes in females fed on L. rhamnosus (PROBIO) and in control females (CTRL). Data are given as mean \pm s.D. $(n=3)$. Asterisks denote significant differences from the control group $(P<0.05)$ analyzed using Student's $t$-test.

\section{Discussion}

Reproduction is gated by the state of body energy reserves and is sensitive to different metabolic cues; the neuroendocrine mechanisms responsible for the tight coupling between energy homeostasis and fertility are represented by metabolic hormones and neuropeptides that integrate the hypothalamic center governing reproduction, controlling the expression and release of Gnrh (Fernandez-Fernandez et al. 2006, Castellano et al. 2009, Kitahashi et al. 2009, Zohar et al. 2010). Thus, full activation of the hypothalamic-pituitarygonadal axis at puberty and its proper functioning in adulthood critically depend on adequate body energy stores (Hill et al. 2008). The identification of the adipose hormone leptin, which signals the magnitude of energy stores to the hypothalamic centers governing reproduction (Casanueva \& Dieguez 1999, Goumenou et al. 2003), represented an important step toward understanding the mechanisms controlling this interplay.

In this study, for the first time, a possible stimulating role of $L$. rhamnosus on female zebrafish fecundity was investigated. The results suggest that the probiotic may act indirectly by activating a potent metabolic hormone such as leptin. In mammals, it was well established that leptin can regulate reproduction by acting on the hypothalamus (modulating gnrh mRNA transcription and release) and on the pituitary (modulating /h gene expression and release) as evidenced by several authors (Smith et al. 2002, Barb et al. 2005).

In this study, the expression of the lep gene was significantly induced after probiotic administration in the gut. Concomitantly, we also observed the induction of 


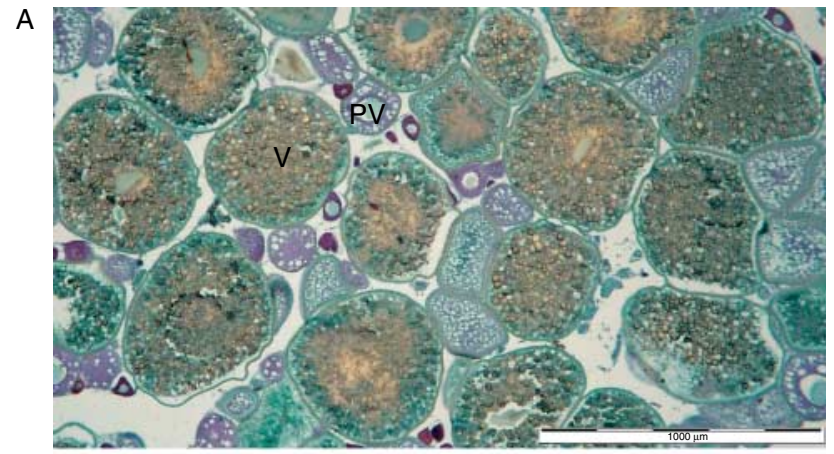

B

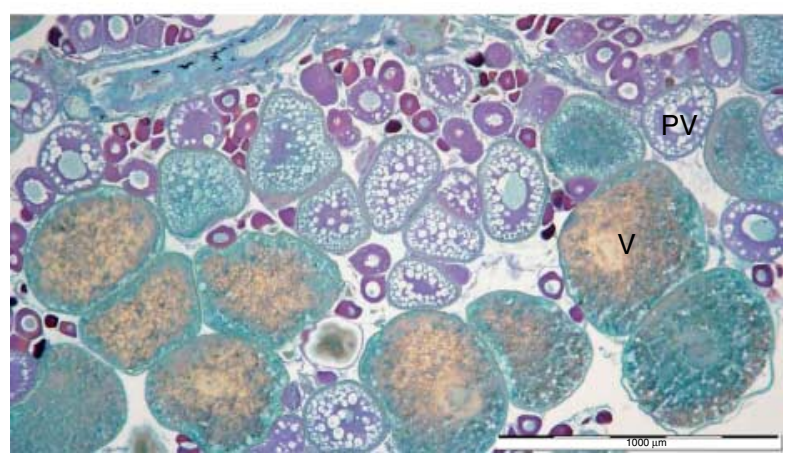

Figure 6 Representative micrographs of ovaries from (A) females fed on L. rhamnosus and (B) control females. PV, previtellogenic follicles; $\mathrm{V}$, vitellogenic follicles.

lep gene transcription in the brain. These increases were correlated with a higher expression of kiss 1, kiss2, and, in turn, gnrh3 genes found in the brain of treated females.

The stimulatory role of $L$. rhamnosus on female zebrafish fecundity may be due both to the activation of the endocrine control described above and to the direct action of leptin on the ovary. In mammals, binding of circulating or locally produced leptin to its receptor may lead to direct modulation of ovarian function by controlling the process of gonadal steroidogenesis (Moschos et al. 2002). Expression of the leptin receptor (lepr) mRNA has been identified in adult human

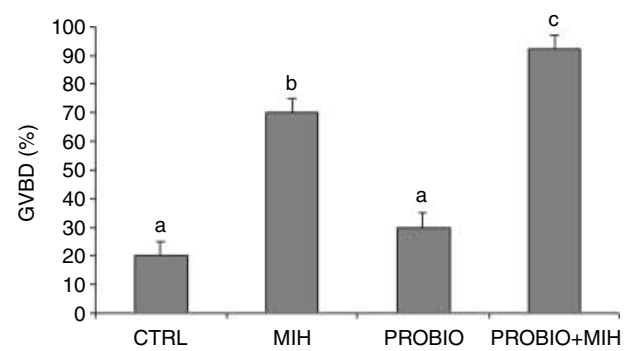

Figure 7 Rate (\%) of GVBD in Danio rerio stage IIIb follicles isolated from control groups ovary incubated in L15 (CTRL) and L15 + MIH $(1 \mu \mathrm{g} / \mathrm{ml}, \mathrm{MIH})$ and in D. rerio stage IIlb follicles isolated from treated groups ovary incubated in L15 (PROBIO) and L15 + MIH (PROBIO+ $\mathrm{MIH}$ ). Each data represents means of three independent observations \pm s.D. Different letters indicate significant differences on the basis of the Bonferroni post-test $(P<0.05)$.

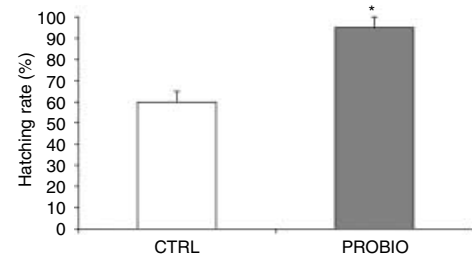

Figure 8 Hatching rate calculated as the percent of number of viable larvae after hatch divided by the number of fertilized eggs $(n=10)$, in triplicate. Results are expressed as means \pm s.D. Statistically significant differences between the experimental groups were tested with Student's $t$-test $(P<0.05)$.

granulosa, theca, and interstitial cells (Cioffi et al. 1997, Karlsson et al. 1997), as well as in the rat (Zamorano et al. 1997), in the porcine (Lin et al. 2000) and in the bovine (Spicer \& Francisko 1998) ovaries. In zebrafish, Liu et al. (2010) have recently found lepr expression in the adult fish brain and also in several adult tissues including liver, muscle, and gonads.

The results of our study demonstrated the stimulatory role of $L$. rhamnosus administration as a feed additive in zebrafish $(D$. rerio) follicle maturation. In particular, these findings suggested $L$. rhamnosus administration can control the expression of tgfb 1 and bmp15 mRNA levels which, in turn, can modulate cbr1l, Ihcgr, and paqr8 gene expression. In fact, previous studies on zebrafish have described how treatment with recombinant human TGFB1 inhibits oocyte maturation reducing Lh activity by decreasing Ihcgr and cbr1/ mRNA levels, and have shown decreased basal and hCG-induced paqr8 mRNA levels in zebrafish follicles (Kohli et al. 2005). Similar results have also been obtained with recombinant human $B M P 15$, which also reduced hCG-induced oocyte maturation (Clelland et al. 2006). Moreover, the knockdown of bmp15 in oocytes, by antisense oligonucleotides, increased paqr8 expression (Tan et al. 2009), and the inhibition of bmp15 expression or function in class Illa follicles has been found to induce their sensitivity to MIH (Clelland et al. 2006, 2007).

The mechanisms through which L. rhamnosus stimulates lep gene expression both at central and at peripheral levels are still unknown, and further studies are needed in order to clarify this aspect.

In conclusion, the stimulatory role of L. rhamnosus administration as a feed additive in zebrafish follicle maturation, fecundity, and egg quality illustrated in this study indicates the great potential of this feed additive for ovarian physiology and presumably for embryo development.

Considering that the zebrafish has been established as a vertebrate model system that is useful for biomedical research, the results obtained here may also have a potential application in reproduction technology for all vertebrates, including mammals. 
Table 1 Hatching time of embryos deriving from control or treated females.

\begin{tabular}{lc}
\hline & Hatching time $(\mathrm{hpf})$ \\
\hline Control & $48 \pm 1$ \\
Treated & $44 \pm 1$ \\
\hline
\end{tabular}

\section{Materials and Methods}

\section{Animals and probiotic administration}

Adult female and male zebrafish (D. rerio) were purchased from a local supplier, Acquario di Bologna, Bologna, Italy. The fish were acclimatized to the laboratory conditions and observed for clinical health for 4 weeks prior to start experiments. The animals were kept in $50 \mathrm{I}$ glass tanks under controlled conditions $\left(28 \pm 0.5^{\circ} \mathrm{C}\right.$ and $14 \mathrm{~h}$ light: $10 \mathrm{~h}$ darkness). The fish were fed on $1.5 \mathrm{~g}$ Tetramin (Tetra, Melle, Germany) granules twice a day.

Experiments were performed on two groups: control groups (CTRL) that were fed only on commercial diet and treated groups (PROBIO) that were fed on commercial diet mixed with lyophilized probiotic. The experiment was repeated three times.

The probiotic strain used was L. rhamnosus IMC 501, provided by Synbiotec s.r.I. (Camerino, MC, Italy) and supplied in a final concentration in the tank water of $10^{6} \mathrm{CFU} / \mathrm{ml}$ as suggested by the producer.

The count of egg spawned output was performed every day at $0900 \mathrm{~h}$ within $1 \mathrm{~h}$ after lights. The embryos were then transferred to a nursery tank and monitored till the hatching.

After 10 days of treatment, 10 females from each experimental group were killed by a lethal overdose of anesthesia (500 mg/l MS-222 (3-aminobenzoic acid ethyl ester) buffered to $\mathrm{pH}$ 7.4; Sigma). The brain, gut, and ovary were sampled and immediately poured in liquid nitrogen and stored at $-80^{\circ} \mathrm{C}$ until molecular biological analyses were performed. Five gonads from each experimental group were removed and fixed in an aqueous solution of Bouin's fixative.

Procedures were performed in accordance with the Guidelines on the handling and Training of Laboratory Animals by the Universities Federation for Animal Welfare (UFAW) and with the Italian animal welfare legislation (D.L. 116/92).

\section{Histological study}

Fixed gonads were prepared for histological examination using standard biological procedures. Gonads were embedded in paraffin wax and sectioned $(7 \mu \mathrm{m})$ with a microtome (HM 355 Microm). The sections were stained using picroindigocarmine (Fluka no. 57 000) and mounted in Afcolene, and then examined under a light microscope (Nikon 90i) with the software NIS element AR.

\section{RNA extraction and cDNA synthesis}

Total RNA was extracted from tissues using Minikit RNeasy (Qiagen) extraction kit following the manufacturer's protocol. Total RNA extracted was eluted in $25 \mu$ R Rase-free water. Final RNA concentrations were determined by spectrophotometer, and the RNA integrity was verified by ethidium bromide staining of $28 \mathrm{~S}$ and $18 \mathrm{~S}$ ribosomal RNA bands on $1 \%$ agarose gel. RNA was stored at $-80^{\circ} \mathrm{C}$ until use.

Total RNA was treated with DNase $\left(10 \mathrm{UI}\right.$ at $37^{\circ} \mathrm{C}$ for 10 min; MBI Fermentas, Glen Burnie, MD, USA), and a total amount of $1 \mu \mathrm{g}$ RNA was used for cDNA synthesis, employing iScript cDNA Synthesis kit (Bio-Rad).

\section{Real-time PCR}

PCR were performed with SYBR Green method in an iQ5 iCycler thermal cycler (Bio-Rad). Triplicate PCR were carried out for each sample analyzed. The reactions were set on a 96-well plate by mixing, for each sample, $1 \mu$ l diluted $(1 / 20)$ cDNA, $5 \mu \mathrm{l} 2 \times$ concentrated iQ SYBR Green Supermix (Bio-Rad), containing SYBR Green as a fluorescent intercalating agent, $0.3 \mu \mathrm{M}$ forward primer and $0.3 \mu \mathrm{M}$ reverse primer. The thermal profile for all the reactions was $3 \mathrm{~min}$ at $95^{\circ} \mathrm{C}$ and then 45 cycles of $20 \mathrm{~s}$ at $95^{\circ} \mathrm{C}, 20 \mathrm{~s}$ at $60{ }^{\circ} \mathrm{C}$, and $20 \mathrm{~s}$ at $72{ }^{\circ} \mathrm{C}$. Fluorescence monitoring occurred at the end of each cycle. Additional dissociation curve analysis was performed, and it showed one single peak in all cases.

$\beta$-actin and gapdh were used as housekeeping genes in each sample to standardize the results by eliminating variation in mRNA and cDNA quantity and quality. No amplification product was observed in negative control, and no primerdimer formation was observed in the control templates. The data obtained were analyzed using the iQ5 optical system

Table 2 List of primers used for real-time PCR analyses.

\begin{tabular}{|c|c|c|}
\hline Genes & Forward primer & Reverse primer \\
\hline lep & AGCTCTCСGСТСААССТGTA & CAGCGGGAATCTCTGGATAA \\
\hline kiss1 & ACAGACACTCGTCCCACAGATG & CAATCGTGTGAGCATGTCCTG \\
\hline kiss2 & ATTCTCTTCATGTCTGCAATGGTCA & TGCTTTCTCAGGTAAAGCATCATTG \\
\hline gnrh3 & TTAGCATGGAGTGGAAAGGAAGGTTG & СТTTCAGAGGCAAACCTTCAGCAT \\
\hline tgfb1 & TCGCTTTGTCTCCAAGGACT & TGCAAGAGAGTTGCCATTTG \\
\hline bmp15 & AGGGTGACCGGATCACTATG & TGCTGCCAGACTTTTTAGACC \\
\hline gdf9 & СGАССАСААССАССТСТСТСС & GGGACTGAGTGCTGGATGCC \\
\hline Ihcor & GGCGAAGGCTAGATGGCACAT & TCGCCATCTGGTTCATCAATA \\
\hline cbr11 & TCATGCTCTTCTGCCGATAC & CAAGGGACTTCTTGCTGACA \\
\hline paqr8 & CAACGAGCTGCTGAATGTGT & GGGCCAGTTCAGAGTGAGAC \\
\hline$\beta$-actin & GGTACССАТСТССТGСТССАA & GAGCGTGGCTACTCСТTCACC \\
\hline gapdh & GTGTAGGCGTGGACTGTGGT & GTGTAGGCGTGGACTGTGGT \\
\hline
\end{tabular}


software version 2.0 (Bio-Rad). Modification of the gene expression is represented with respect to the control sampled at the same time of the treatment. In Table 2, the sequences of specific primers used were reported.

\section{Follicles in vitro maturation assay}

In vitro maturation assays were conducted as described previously (Clelland et al. 2006). The ovaries were teased into separate follicles using transfer pipettes (Samco Scientific Corp., San Fernando, CA, USA) without trypsinization. Therefore, stage IIIb follicles were separated according to diameters measuring (Selman et al. 1993, Wu et al. 2000) with an ocular micrometer under a dissecting microscope and sampled. Stage IIIb follicles derived from both the control and treated groups were incubated in $1 \mathrm{ml} \mathrm{L15}$ medium at $25^{\circ} \mathrm{C}$ in 24 -well culture plates. For experimental purpose, incubations were carried out separately: stage IIIb follicles isolated from control groups ovary were incubated in L15 (CTRL) and L15 + MIH $(1 \mu \mathrm{g} / \mathrm{ml})$ $(\mathrm{MIH})$; stage IIIb follicles isolated from treated groups ovary were incubated in L15 (PROBIO) and L15+MIH $(1 \mu \mathrm{g} / \mathrm{ml})$ $(\mathrm{PROBIO}+\mathrm{MIH})$. Maturation was scored after $18 \mathrm{~h}$ of incubation. Follicles that underwent GVBD could be identified by their acquired translucency. Each experiment was conducted in four wells with $\sim 20$ follicles per well, and all the experiments were repeated three times.

\section{Statistical analysis}

Data presented are mean \pm s.D. for the number of experiments. Student's $t$-test was used for comparison between the two experimental groups. $P<0.05$ was considered significant.

In vitro maturation results were examined by one-way ANOVA followed by the Bonferroni's multiple comparison test, using a statistical software package Prism5 (GraphPad Software Inc., San Diego, CA, USA) with significance set at $P<0.05$.

\section{Declaration of interest}

The authors declare that there is no conflict of interest that could be perceived as prejudicing the impartiality of the research reported.

\section{Funding}

This work was supported by 'Fondi d'Ateneo 2009' grant to O Carnevali.

\section{Acknowledgements}

The authors wish to thank Dr Cecilia Totti and Dr Chiara Pennesi for their technical assistance and support with microscopy; Madame Chantal Cuty, director of the plateau technique d'histologie of INRA-SCRIBE Rennes-francia for the support for the histological study; Synbiotech for providing probiotic; and OceAN soc coop for the technical support at the facilities.

\section{References}

Barb CR, Hausman GJ \& Czaja K 2005 Leptin: a metabolic signal affecting central regulation of reproduction in the pig. Domestic Animal Endocrinology 29 186-192. (doi:10.1016/j.domaniend.2005.02.024)

Casanueva F \& Dieguez C 1999 Neuroendocrine regulation and actions of leptin. Frontiers in Neuroendocrinology 20 317-363. (doi:10.1006/frne. 1999.0187)

Castellano JM, Roa J, Luque RM, Dieguez C, Aguilar E, Pinilla L \& Tena-Sempere M 2009 KiSS-1/kisspeptins and the metabolic control of reproduction: physiologic roles and putative physiopathological implications. Peptides 30 57-66. (doi:10.1016/j.peptides.2008.06.007)

Cioffi JA, Van Blercom J, Antczak M, Shafer A, Wittmer S \& Snodgrass HR 1997 The expression of leptin and its receptors in pre-ovulatory human follicles. Molecular Human Reproduction 3 467-472. (doi:10.1093/ molehr/3.6.467)

Clelland E \& Peng C 2009 Endocrine/paracrine control of zebrafish ovarian development. Molecular and Cellular Endocrinology 312 42-52. (doi:10.1016/j.mce.2009.04.009)

Clelland E, Kohli G, Campbell RK, Sharma S, Shimasaki S \& Peng C 2006 Bone morphogenetic protein-15 in the zebrafish ovary: complementary deoxyribonucleic acid cloning, genomic organization, tissue distribution, and role in oocyte maturation. Endocrinology 147 201-209. (doi:10.1210/en.2005-1017)

Clelland E, Tan Q, Balofsky A, Lacivita R \& Peng C 2007 Inhibition of premature oocyte maturation: a role for bone morphogenetic protein 15 in zebrafish ovarian follicles. Endocrinology 148 5451-5458. (doi:10. 1210/en.2007-0674)

Fernandez-Fernandez R, Martini AC, Navarro VM, Castellano JM, Dieguez C, Aguilar E, Pinilla L \& Tena-Sempere M 2006 Novel signals for the integration of energy balance and reproduction. Molecular and Cellular Endocrinology 254 127-132. (doi:10.1016/j.mce.2006.04.026)

Fishman MC 2001 Genomics: zebrafish - the canonical vertebrate. Science 294 1290-1291. (doi:10.1126/science.1066652)

Goumenou AG, Matalliotakis IM, Koumantakis GE \& Panidis DK 2003 The role of leptin in fertility. European Journal of Obstetrics, Gynecology, and Reproductive Biology 106 118-124. (doi:10.1016/S0301-2115(02) 00359-7)

Hanna RN \& Zhu Y 2009 Expression of membrane progestin receptors in zebrafish (Danio rerio) oocytes, testis and pituitary. General and Comparative Endocrinology 161 153-157. (doi:10.1016/j.ygcen.2008. 10.006)

Hill JW, Elmquist JK \& Elias CF 2008 Hypothalamic pathways linking energy balance and reproduction. American Journal of Physiology. Endocrinology and Metabolism 294 827-832. (doi:10.1152/ajpendo. 00670.2007)

Karlsson C, Lindell K, Svensson E, Bergh C, Lind P, Billig H, Carlsson LM \& Carlsson B 1997 Expression of functional leptin receptors in the human ovary. Journal of Clinical Endocrinology and Metabolism 82 4144-4148. (doi:10.1210/jc.82.12.4144)

Keller ET, Keller JM \& Gillespie G 2006 The use of mature zebrafish (Danio rerio) as a model for human aging and disease. Handbook of Models for Human Aging, pp 309-316. Ed. PM Conn. Burlington, MA: Elsevier Academic Press.

Kitahashi T, Ogawa S \& Parhar IS 2009 Cloning and expression of Kiss 2 in the zebrafish and Medaka. Neuroendocrinology 150 821-831. (doi:10.1210/en.2008-0940)

Kohli G, Clelland E \& Peng C 2005 Potential targets of transforming growth factor- $\beta 1$ during inhibition of oocyte maturation in zebrafish. Reproductive Biology and Endocrinology 3 53-44. (doi:10.1186/ 1477-7827-3-53)

Lin J, Barb CR, Matteri RL, Kraeling RR, Chen X, Meinersmann RJ \& Rampacek GB 2000 Long form leptin receptor mRNA expression in the brain, pituitary, and other tissues of the pig. Domestic Animal Endocrinology 19 53-61. (doi:10.1016/S0739-7240(00)00064-3)

Liu L \& Ge W 2007 Growth differentiation factor 9 and its spatiotemporal expression and regulation in the zebrafish ovary. Biology of Reproduction 76 294-302. (doi:10.1095/biolreprod.106.054668)

Liu Q, Chen Y, Copeland D, Ball H, Duff RJ, Rockich B \& Londraville RL 2010 Expression of leptin receptor gene in developing and adult zebrafish. General and Comparative Endocrinology 166 346-355. (doi:10.1016/j.ygcen.2009.11.015) 
Manley KJ, Fraenkel MB, Mayall BC \& Power DA 2007 Probiotic treatment of vancomycin-resistant enterococci: a randomised controlled trial. Medical Journal of Australia 186 454-457.

Moschos S, Chan JL \& Mantzoros CS 2002 Leptin and reproduction: a review. Fertility and Sterility 77 433-444. (doi:10.1016/S0015-0282 (01)03010-2)

Nagahama Y, Yoshikuni M, Yamashita M, Tokumoto T \& Katsu Y 1995 Regulation of oocyte growth and maturation in fish. Current Topics in Developmental Biology 30 103-145. (doi:10.1016/S0070-2153(08) 60565-7)

Pant N, Marcotte H, Brussow H, Svensson L \& Hammarstrom L 2007 Effective prophylaxis against rotavirus diarrhea using a combination of Lactobacillus rhamnosus GG and antibodies. BMC Microbiology 7 86-89. (doi:10.1186/1471-2180-7-86)

Patino R, Yoshizaki G, Thomas P \& Kagawa H 2001 Gonadotropic control of ovarian follicle maturation: the two-stage concept and its mechanisms. Comparative Biochemistry and Physiology. Part B, Biochemistry \& Molecular Biology 129 427-439. (doi:10.1016/S10964959(01)00344-X)

Penberthy WT, Shafizadeh E \& Lin S 2002 The zebrafish as a model for human disease. Frontiers in Bioscience 7 1439-1453. (doi:10.2741/ penber)

Selman K, Wallace RA, Sarka A \& Qi X 1993 Stages of oocyte development in the zebrafish, Brachydanio rerio. Journal of Morphology 218 203-224. (doi:10.1002/jmor.1052180209)

Shiels HA, Cros C, Dixey H, Wilson C, Luxan G \& Brette F 2009 The zebrafish heart - a suitable model for human cardiology? Comparative Biochemistry and Physiology. Part A, Molecular \& Integrative Physiology 153 S84-S89. (doi:10.1016/j.cbpa.2009.04.071)

Smith GD, Jackson LM \& Foster DL 2002 Leptin regulation of reproductive function and fertility. Theriogenology 57 73-86. (doi:10.1016/S0093691X(01)00658-6)

Spicer LJ \& Francisko CC 1998 Adipose obese gene product, leptin, inhibits bovine ovarian thecal cells steroidogenesis. Biology of Reproduction 58 207-212. (doi:10.1095/biolreprod58.1.207)

Sumanas S \& Lin S 2004 Zebrafish as a model system for drug target screening and validation. Drug Discovery Today: Targets 3 89-96. (doi:10.1016/S1741-8372(04)02428-4)
Szajewska H, Skorka A, Ruszczynski M \& Gieruszczak Bialek D 2007 Meta-analysis: Lactobacillus GG for treating acute diarrhoea in children. Alimentary Pharmacology \& Therapeutics 25 871-881. (doi:10.1111/ j.1365-2036.2007.03282.x)

Tan Q, Balofsky A, Weisz K \& Peng C 2009 Role of activin, transforming growth factor- $\beta$ and bone morphogenetic protein 15 in regulating zebrafish oocyte maturation. Comparative Biochemistry and Physiology. Part A, Molecular \& Integrative Physiology 153 18-23. (doi:10.1016/ j.cbpa.2008.09.016)

Verdenelli MC, Ghelfi F, Silvi S, Orpianesi C, Cecchini C \& Cresci A 2009 Probiotic properties of Lactobacillus rhamnosus and Lactobacillus paracasei isolated from human faeces. European Journal of Nutrition 48 355-363. (doi:10.1007/s00394-009-0021-2)

Wang Y \& Ge W 2003a Involvement of cyclic adenosine 3',5' monophosphate in the differential regulation of activin betaA and betaB expression by gonadotropin in the zebrafish ovarian follicle cells. Endocrinology 144 491-499. (doi:10.1210/en.2002-220734)

Wang Y \& Ge W 2003b Spatial expression patterns of activin and its signaling system in the zebrafish ovarian follicle: evidence for paracrine action of activin on the oocytes. Biology of Reproduction 69 1998-2006. (doi:10.1095/biolreprod.103.020826)

Wu J, Nayudu PL, Kiesel PS \& Michelmann HW 2000 Luteinizing hormone has a stage-limited effect on preantral follicle development in vitro. Biology of Reproduction 63 320-327. (doi:10.1095/biolreprod63.1.320)

Zamorano PL, Mahesh VB, DeSevilla LM, Chorich LP, Bhat GK \& Brann I 1997 Expression and localization of the leptin receptor in endocrine and neuroendocrine tissues of the rat. Neuroendocrinology 65 223-228. (doi:10.1159/000127276)

Zohar Y, Muñoz-Cueto JA, Elizur A \& Kah O 2010 Neuroendocrinology of reproduction in teleost fish. General and Comparative Endocrinology 165 438-455. (doi:10.1016/j.ygcen.2009.04.017)

Received 18 March 2010

First decision 3 June 2010

Revised manuscript received 28 July 2010

Accepted 8 September 2010 